\title{
Effective Protection Redux*
}

\author{
James E. Anderson
}

August, 1995

\begin{abstract}
$\underline{\text { Abstract }}$
This paper rehabilitates effective protection. In general equilibrium, the usual definition (the percentage change in value added per unit induced by the tariff structure) corresponds to no economically interesting magnitude. The effective rate of protection for sector $\mathrm{j}$ is defined here as the uniform tariff which is equivalent to the actual differentiated tariff structure in its effect on the rents to residual claimants in sector $\mathrm{j}$. This definition applies to general as well as partial equilibrium economic structures, has obvious relevance for political economy models and seems to correspond to the motivation for the early effective protection literature. Like the earlier effective rate formula, the concept is operational using the widely available set of Computable General Equilibrium (CGE) models. An example is provided for the US economy. The numerical results for the old and new concepts are not significantly correlated.
\end{abstract}

JEL Classification: F13, D72.

For presentation to the European Economic Association meetings, Prague, September, 1995.

Communications to:

James E. Anderson

Dept of Economics

Boston College

Chestnut Hill, MA 02167

\footnotetext{
* With apologies to John Updike. According to the Oxford English Dictionary, redux: of crepitation or other physical signs, indicating the return of an organ to a healthy state. From the Latin root reducere, to bring back.
} 


\section{Introduction}

Effective protection is the ranch house of trade policy construction --- ugly but too useful not to be used. Building to the blueprint of theorists such as Corden (1966), a generation of applied economists have calculated effective rates of protection while cheerfully ignoring the critique of the design best summarized by Ethier (1977). ${ }^{1} \quad$ In academic circles this work is ignored, while outside the academy it is either apologized for or trashed. Academics surveying the theory of protection (for example Dixit, 1985 and Anderson, 1994) cover effective protection since it is too practically important to ignore, but awkwardly, since the critique of the concept is so convincing.

This paper rehabilitates effective protection by carefully defining the question the resulting index number is supposed to answer. The usual definition of the effective rate of protection is the percentage change in value added per unit induced by the tariff structure. The problem is that in general equilibrium this measure corresponds to no economically interesting magnitude. ${ }^{2}$ In contrast, the effective rate of protection for sector $\mathrm{j}$ is defined here as the uniform tariff which is equivalent to the actual differentiated tariff structure in its effect on the rents to residual claimants in sector $\mathrm{j}$. This definition applies to general as well as partial equilibrium economic structures, though resulting in a different formula in each structure. The new definition has obvious relevance for political economy models and seems to correspond to the motivation for the early effective protection literature. The concept is defined for all economic structures in which sectoral residual claims exist.

Like the earlier effective rate, the new definition is operational. In the last generation, Computable General Equilibrium (CGE) models have become fairly widely

\footnotetext{
${ }^{1}$ See also Anderson (1970), Ethier (1971), and Tan (1970).

2Under the restriction of value added separability, meaning attaches to the notion of protection to value added in the form of increases in a 'price' of value added. This is too restrictive to make the effective rate of protection generally useful. Moreover, there seems to be no good reason to make the protection of sectoral value added a central focus.
} 
available, and such models are readily adapted to calculate the effective rate of protection on each sector. An example is provided here using the USDA/ERS agricultural CGE model distributed in the GAMS (General Algebraic Modeling System) library. The results show that the effective rates calculated with the new and old definitions are not significantly correlated. Most important from a practical view, in 3 of 10 sectors the sign of protection is reversed, including 3 of 5 of the agricultural sectors which are the focus of the model.

Several antecedents in the literature emphasize the possible usefulness of the standard measure of effective protection in analyzing sector specific factor returns. Jones (1975) characterized the loose but still useful relationship between the set of specific factor returns and the set of effective rates of protection in the Ricardo-Viner (one mobile factor and many sector specific factors) case. The theme that effective protection might usefully be linked to distribution and hence political economy was echoed by Ethier (1977) in his conclusion. Just recently, Kohler (1991) applied this idea in a study of Austrian tariff structure. Nevertheless, only in very special cases can the ranking (or sign) of the usual measure of effective protection replicate the ranking (or sign) of sector specific factor income changes.

In contrast to this literature, the present paper redefines the effective protection measure to by definition avoid the problems which complicate the link between specific factor returns on the one hand and measures of effective protection on the other hand. Given a CGE model, the analyst can always compute the sector specific factor income changes due to the protection structure. Differences in these income changes across sectors reflect both the structure of protection (which the old effective protection concept tried to measure) and differences in the position of the sectoral factor in the technology. The two questions, 'how much protection is given' and 'how much does income change as a result' are distinct. The new concept gives a precise answer to the first question. 
The main business of the paper is to characterize the new concept and relate it to the old one. Neat and elegant results are obtained by applying modern index number and duality theory. Related work on tariff index numbers to answer different questions is in Anderson and Neary $(1994,1995)$. In a special case, that of partial equilibrium with fixed coefficients of production, the formula implied by the new definition is identical to the usual effective rate of protection formula. With variable coefficients but still in partial equilibrium, the formula is a simple variant on the usual formula, which can be treated as an approximation. In general equilibrium the usual formula is a component of a decomposition of the formula implied by the new definition. In general the ranking of sectors by the usual formula and the correct formula will differ, though a special case is offered in which the ranking is identical. Using the decomposition the trail leading from the general equilibrium formula to the partial equilibrium formula is clear and straight.

Section I gives the partial equilibrium version of the effective protection index. The special case of fixed coefficients gives the standard formula, while substitution possibilities imply a simple variant. Section II give the general equilibrium version of the effective protection index and shows how it is related to the partial equilibrium index. Section III contrasts the effective protection index to the sector specific factor income change. Section IV takes up a number of extensions of economic structure (imperfect competition, scale economies, nontraded goods) and of the type of distortions (quotas, domestic taxes and subsidies) admitted. In each case, the set of distortions is mapped to a uniform tariff equivalent. Section V presents the empirical results of calculating US effective rates of protection based on the USDA/ERS model in the GAMS library. The old and new measures of effective protection are not significantly correlated. Section VI concludes.

\section{Partial Equilibrium Effective Protection}

A standard neoclassical convex economy is assumed here and in Sections II and III. A set of final and intermediate good prices is distorted by tariffs. In keeping with the 
partial equilibrium setting, all goods prices are exogenously set by the combination of perfect substitutability of foreign and domestic versions of the same good, fixed world prices and given trade policies. Non produced input prices are fixed in this section but are endogenous in Section II. The task is to evaluate the given tariff structure relative to some alternative structure with equivalent effect on rents earned in sector $\mathrm{j}$.

The residual payments or rents to owners of specific factors in sector $\mathrm{j}$ can be aggregated in a sectoral profit function $\pi \mathrm{j}(\mathrm{p}, \mathrm{w})$ with the standard properties. $\pi \mathrm{j}$ should be thought of as including firm and sector specific payments to human capital. ${ }^{3}$ Here, $p$ is the vector of goods prices, including both those for the output of sector $j$ and the outputs of sectors from which sector $\mathrm{j}$ buys inputs. Since domestic distortions are absent, supply and demand prices for intermediate goods are the same. Sector $\mathrm{j}$ can produce a set of outputs. $\mathrm{w}$ is the vector of non produced input prices.

The idea is to find the uniform tariff on all distorted goods which has an effect on profits of $\mathrm{j}$ equivalent to that of the initial tariff structure. Some goods prices are normally not distorted (e.g., those of export sectors), so this qualification matters. The undistorted prices are subsumed into the background with prices equal to one. Let the initial price vector for distorted goods be denoted $\mathrm{p}^{0}$ and the free trade price vector be denoted $\mathrm{p}^{1}$. Let the price vector for nontraded inputs be denoted $\mathrm{w}^{0}$ which by assumption of partial equilibrium is unchanged with respect to the change in $p$. The effective protection index $\mathrm{e}^{\mathrm{j}}$ for sector $\mathrm{j}$ in partial equilibrium is defined implicitly as:

$$
\begin{aligned}
& e^{j}=1 / d^{j}\left(p^{1} ; w^{0}, p^{0}\right)-1, \text { where } \\
& d^{j}\left(p^{1} ; w^{0}, p^{0}\right)=d \mid \pi^{j}\left(p^{1} / d, w^{0}\right)=\pi\left(p^{0}, w^{0}\right) .
\end{aligned}
$$

The function d is the distance function (Deaton, 1979 and Deaton and Muellbauer, 1984) applied in the space of tariff distorted prices. ${ }^{4}$ Working backwards, $\mathrm{d}^{\mathrm{j}}$ is the uniform

\footnotetext{
${ }^{3}$ The profit function is usually justified by appeal to the maximization activity of an actual firm. However, the hypothesis of competition implies that the collection of interests in specific factors within each sector can be modeled as if maximizing rent.

${ }^{4}$ In related work, Anderson and Neary apply the distance function to define a tariff index which holds real income of a representative agent constant.
} 
output price deflator which maintains profits in $\mathrm{j}^{5}{ }^{5}$ Since $\mathrm{p}^{1}$ is lower than $\mathrm{p}^{0}$, $\mathrm{d}^{\mathrm{j}}$ is less than one, and is equal to the inverse of a uniform tariff factor. Then ej is equal to the uniform tariff on distorted goods which has the same effect on the profits of sector $j$ as the initial tariff vector.

Several extensions of (1) are immediate. First, it is possible to define a uniform tariff (export tax/subsidy) vector which includes currently undistorted goods, but this seems much less useful for the purpose of political economy analysis, so it will be treated only as a special case. Second, the effective rate of protection defined in (1) can formally be applied to comparing any two distortion structures. If $\mathrm{p}^{1}$ represents a partial tariff reform price vector rather than the free trade price vector, the effective rate defined by (1) is interpreted as the uniform tariff surcharge which is required to make the new protection structure equivalent to theinitial structure in its effect on profits of sector $\mathrm{j}$. Of course, the surcharge could be negative if $\mathrm{p}^{1}$ represents an increase in protection. This extension is practically significant, since many comparisions are in practice between one distortion structure and another.

In the special case of (i) nonjoint outputs, (ii) in which all intermediate goods prices are distorted and (iii) fixed coefficients, the formula for ej is identical to the usual formula for the effective rate of protection. Elsewhere, it has a simple relationship to the usual formula. To see this it is helpful to begin with the case of small changes in the prices, due to small tariffs. (Alternatively $\mathrm{p}^{1}$ need not be interpreted as the free trade price vector, just a price vector close to $\mathrm{p}^{0}$.) The proportional rate of change of ej is equal to minus the proportional rate of change of $\mathrm{dj}$. The latter is equal to

\footnotetext{
5 The existence and uniqueness of $d$ is guaranteed if $\pi$ is monotonic with respect to uniform changes in $p$; $\pi_{\mathrm{p}} \mathrm{p}$ is one-signed. For sectors which receive no output protection $\pi_{\mathrm{p}}{ }^{\prime} \mathrm{p}$ is negative, since $\pi_{\mathrm{p}}$ is equal to minus the input demand vector. For sectors which receive some protection, $\pi_{\mathrm{p}}$ ' $\mathrm{p}$ is equal to 'value added by undistorted' factors. It is possible for value added to be negative at free trade prices, and positive at protected prices (see Tan, 1970), implying a sign change in $\pi_{\mathrm{p}}$ 'p. This implies there may be two solutions for $\mathrm{d}$, or none. If there are two, the region of negative value added is surely also the region of negative profit. If the base profit is positive (a plausible condition) the solution for $\mathrm{d}$ must be sought in the region where $\pi\left(\mathrm{p}^{1} / \mathrm{d}, \mathrm{w}^{0}\right)$ is positive.
} 


$$
-\hat{d}^{j}=\frac{\pi_{p}^{j{ }^{\prime}} d p}{\pi_{p}^{j^{\prime} p}} .
$$

Here the subscript $\mathrm{p}$ denotes partial differentiation, the ${ }^{\wedge}$ denotes proportional rate of

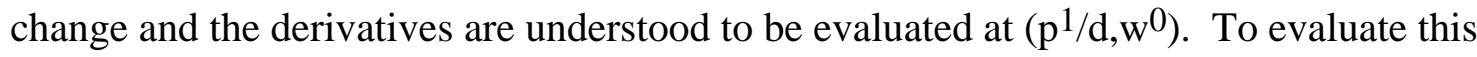
expression, first use Hotelling's Lemma ${ }^{6}$ and then impose (i) nonjoint production (only one output price) and (ii) the condition that all intermediate input prices are distorted, hence included in $\mathrm{p}$. Then divide numerator and denominator by the value of total output of $\mathrm{j}$ to obtain:

$$
-\hat{d}^{j}=-\frac{\hat{p}_{j}-\sum_{i} \alpha_{i j} \hat{p}_{i}}{1-\sum_{i} \alpha_{i j}},
$$

where the $\alpha_{\mathrm{ij}} \mathrm{s}$ are the intermediate input cost shares in the jth sector. Note that these are

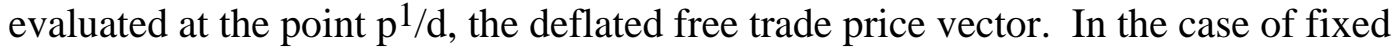
intermediate input coefficients, equation (2) applies to discrete changes in price. The discrete form of $\hat{\mathrm{p}}_{\mathrm{j}}$ is equal to $-\mathrm{t}_{\mathrm{j}}$, the negative of the ad valorem tariff applied to imports of $\mathrm{j}$. Then

$$
\hat{e}^{j}=\frac{t_{j}-\sum \alpha_{i j} t_{i}}{1-\sum \alpha_{i j}},
$$

the usual formula for the effective rate of protection.

For more general protection structures, in which some intermediate inputs are not distorted, the denominator in (3) becomes 'value added by undistorted inputs'. For more general production structures, the 'own price' becomes a price index for jointly produced products and the discrete form of (2) can be evaluated exactly using an intermediate value of the derivatives (the shares) in the formula. The Divisia form of the effective protection index averages the shares at $\mathrm{p}^{0}$ and $\mathrm{p}^{1 / \mathrm{d}}$ as an approximation. Index number theory

\footnotetext{
${ }^{6}$ The derivatives of the profit function with respect to output prices are equal to the vector of outputs and with respect to input prices are equal to minus the vector of inputs.
} 
gives other approximations which nod at substitution effects in the absence of information about shares at the two prices. ${ }^{7}$ But (1) is fundamental and can be calculated directly with an explicit functional form for the profit function, or an implicit form such as the translog, or even supply structures for which the profit function must be evaluated with numerical integration.

\footnotetext{
${ }^{7}$ The early literature had extensive discussion of substitution and possible bias, but was not informed by the focus of this paper. See for example Anderson and Naya (1969).
} 


\section{General Equilibrium Effective Protection}

In general equilibrium, the non produced factors of production have factor prices which are endogenous, and nontraded goods may have prices which change as well. Nontraded goods are suppressed as inessential until Section IV. The sum of all profits is defined as $\Pi=\Sigma \pi \mathrm{j}$. The payments to all factors (including residual claimants) is equal to gross domestic product. Let $\mathrm{v}$ denote the fixed supply of non produced factors which are mobile between sectors at price $\mathrm{w}$, and let $\mathrm{k}$ denote the vector of sector specific factors The vector $\mathrm{k}$ is a convention, not necessarily associated with any measurable factor, which accounts for diminishing returns and thus positive profits which go to residual claimants. A sectoral profits structure is required for a meaningful definition of the interests of a 'sector' in general equilibrium, which seems to be the motivation for the effective protection literature.

The gross domestic product function of a competitive economy has well-known properties (Dixit and Norman, 1980). It is useful here to derive it in an alternative fashion. Gross domestic product is defined by:

$$
g(p, v, k)=\min _{w}\left\{w^{\prime} v+\Pi(p, w, k)\right\}
$$

Here, $\mathrm{k}$ is inserted as an explicit argument of the profit function, having been previously implicit. The first order condition of program (4) implies factor market clearance.

Program (4) has a unique global minimum since $\prod$ is strictly convex. ${ }^{8} \mathrm{~g}_{\mathrm{p}}$ is equal to the vector of general equilibrium net (final) supply functions of the economy. ${ }^{9} \mathrm{~g}_{\mathrm{v}}$ is equal to the vector of competitive factor prices for intersectorally mobile factors. $\mathrm{g}_{\mathrm{k}}$ is equal to the vector of the sector specific competitive factor returns. If $\mathrm{k}$ is paid this competitive

\footnotetext{
${ }^{8}$ Strict convexity follows from the sector specific factors imposed on convex technology.

${ }^{9}$ In the usual derivation of $\mathrm{g}$ this property is straightforward. In the present context it follows from noting that the envelope property of $g$ implies that $g_{p}=\prod_{p}$, and $\prod_{p}$ is equal to gross output less total intermediate input use.
} 
return, $\prod_{\mathrm{k}}$ 'k is equal to $\prod$ and similarly each sectoral profit $\pi \mathrm{j}$ is equal to $\pi_{\mathrm{k}_{\mathrm{j}}}^{\mathrm{j}} \mathrm{k}_{\mathrm{j}}$.

Choosing units such that $\mathrm{k}$ is equal to one, $\mathrm{g}_{\mathrm{k}}$ is equal to $\{\pi \mathrm{j}\}$.

The effective rate of protection of sector $\mathrm{j}$ in general equilibrium is defined as the uniform tariff which has effect on the return to specific factor $\mathrm{j}$ equivalent to the initial tariff structure. Equivalently, the sectoral profit $\pi \mathrm{j}$ is held constant in the switch from the initial tariff structure to a uniform tariff structure, since constant $\mathrm{g}_{\mathrm{k}}^{\mathrm{j}}$ implies constant $\pi \mathrm{j}$.

Thus

$$
\begin{aligned}
& E^{j}=1 / D^{j}-1, \quad \text { where } \\
& D^{j}\left(p^{1} ; p^{0}, v, k\right)=D \mid g_{k}^{j}\left(p^{1} / D, v, k\right)=g_{k}^{j}\left(p^{0}, v, k\right), \quad \text { or } \\
& D^{j}\left(p^{1} ; p^{0}, v, k\right)=D \mid \pi^{j}\left(p^{1} / D, w\left(p^{1} / D, v, k\right), k\right)=\pi^{j}\left(p^{0}, w^{0}, k\right)
\end{aligned}
$$

The existence and uniqueness of $\mathrm{D}$ are guaranteed if $\left[\pi_{\mathrm{p}}{ }^{\prime}+\pi_{\mathrm{w}}{ }^{\prime} \mathrm{w}_{\mathrm{p}}\right] \mathrm{p}$ is one signed. This is a restrictive condition, in contrast to the partial equilibrium case, since $\mathrm{w}_{\mathrm{p}} \mathrm{p}$ is subject to magnification effects.

The properties of $\mathrm{E}$ are intuitively characterized by considering local proportional rates of change. As before, minus the proportional rate of change of $\mathrm{Dj}$ is equal to the proportional rate of change of Ej. Using (6) as the output price deflator, the proportional rate of change of $g_{k}$ with respect to $\mathrm{p}$ forms the weights in the index, parallel to the role played by $\pi_{\mathrm{p}}$ in equation (2). The proportional rate of change of $g_{k}$ with respect to output prices is a rich general equilibrium construct with strong properties: own output price elasticities are greater than one and all others are negative (Dixit and Norman, 1980). The value of these general equilibrium inverse elasticities has no simple connection to the input-output coefficients, and involves all the other share and substitution parameters of the production structure in a highly nonlinear form. However, the alternative form of the gross domestic product function developed here permits an intuitive decomposition of the rate of change of $\mathrm{E}^{\mathrm{j}}$ into partial and general equilibrium components. Using definition (6') for the output price deflator, the proportional rate of change of $\mathrm{Dj}$ is equal to: 


$$
-\hat{D}^{j}=-\frac{\pi_{p}^{j \prime} d p+\pi_{w}^{j \prime} w_{p} d p}{\pi_{p}^{j \prime} p+\pi_{w}^{j \prime} w_{p} p} .
$$

The numerator of (7) gives the change in profits of sector $\mathrm{j}$. The normalization term in the denominator of (7) is the effect on sector $\mathrm{j}$ profits of a uniform proportionate $1 \%$ rise in distorted prices $\mathrm{p}$. If all outputs have distorted prices, $\pi \mathrm{j}$ is homogeneous of degree one in $\mathrm{p}$ and $\mathrm{w}$, implying further that $\mathrm{w}$ is homogeneous of degree one in $\mathrm{p}$ by properties of (4); hence $\pi_{\mathrm{p}}{ }^{\prime} \mathrm{p}+\pi_{\mathrm{w}}{ }^{\prime} \mathrm{w}_{\mathrm{p}} \mathrm{p}$ is equal to $\pi$. Then the normalization in (7) is simply profits and the effective rate of protection is equal to the proportional rate of change of profits. With only some output prices distorted, the normalization term is by the contribution to profits of directly and indirectly distorted prices. This term need not be positive. (The simplest case arises when a sector receives no protection directly.)

Now consider a decomposition of (7) into partial and general equilibrium terms. The first terms in both numerator and denominator are the partial equilibrium terms. Equation (7) can then be decomposed as

$$
\begin{aligned}
\hat{E}^{j} & =\hat{e}^{j} \mu^{j}-\sum_{l} s_{j l} \hat{w}_{l}\left(1-\mu^{j}\right), \quad \text { where } \\
\mu^{j} & =\frac{\pi_{p}^{j^{\prime}} p}{\pi_{p}^{j^{\prime}} p+\pi_{w}^{j^{\prime}} w_{p} p},
\end{aligned}
$$

while $s_{j}$ is the share of mobile primary factor payments paid to the lth factor in sector $\mathrm{j} . \mu$ is ordinarily positive (when the numerator is negative the denominator is likely to be negative as well). However, $\mu$ may well exceed one. For example, in the special case of all output prices being distorted, using the homogeneity properties of $\pi$ and w,

$$
\hat{E}^{j}=\hat{e}^{j} \frac{\pi_{p}^{j^{\prime}} p}{\pi^{j}}-\frac{\pi_{w}^{j^{\prime}{ }^{\prime} w_{p} d p}}{\pi_{w}^{j^{\prime}} w}\left(1-\frac{\pi_{p}^{{ }^{\prime}}{ }^{\prime} p}{\pi^{j}}\right) .
$$

Equation (8') shows that in general equilibrium, sectoral profits are affected by the partial equilibrium measure times a magnifying factor $\mu \mathrm{j}$ equal to $\pi_{\mathrm{p}} \mathrm{p} / \pi$ reflecting the fact that profits are only a portion of value added. The second term represents the more complex 
influence of general equilibrium through change in mobile factor prices, and their effect in turn on sectoral profits. Not much can be said in general about this term, as is wellknown.

For one special case the ranking of sectors by $\mathrm{Ej}^{\mathrm{j}}$ and by ej will be the same for small tariff structures. In the pure Ricardo-Viner model there is one intersectorally mobile factor. The weighted average of factor price changes $\Sigma \sum_{1} \mathrm{~s}_{\mathrm{j}} \hat{\mathrm{w}}_{1}$ collapses to $\hat{\mathrm{w}}$ in $\left(8^{\prime}\right)$,

leaving for the Ricardo-Viner case: 10

$$
\hat{E}^{j}=\left(\hat{e}^{j}+\hat{w}\right) \mu^{j}-\hat{w} .
$$

where $\hat{w}$ is equal to a weighted average of the rates of change of $p$ implied by reverting to free trade, the ith weight being equal to $\mathrm{w}_{\mathrm{pi}} \mathrm{p}_{\mathrm{i}} / \mathrm{w}$. (For the Ricardo-Viner model the elasticity of $\mathrm{w}$ with respect to each element of $\mathrm{p}$ is trapped between 0 and 1 , while the homogeneity of degree one of $w$ in $p$ means that the sum of elasticities is equal to one.)

Thus $\hat{\mathrm{w}}$ is negative and equal to the negative of an 'average' tariff.

In the Ricardo-Viner case, if $\left(\hat{e}^{j}+\hat{w}\right)$ is positive for all protected sectors and if $\mu j$ is non decreasing in ej going across sectors, then $E^{j}$ and $e^{j}$ give the same rank of effective protection.

Noting that typical tariff structures are cascaded, so that ej exceeds tj, usually by a large margin, the first condition is fairly plausible for the subset of protected sectors, and necessarily met if the smallest ej exceeds the largest $t \mathrm{j}$. The second condition, that the ratio of value added to profits be non decreasing is a quite restrictive technical condition, showing the nature of the difficulty in relating the usual measure to a correct measure.

How operational is the effective rate of protection defined above? The early effective protection literature was confused by the apparent general equilibrium nature of the partial equilibrium measure d. Effective protection attracted applied economists because it appeared to be an operational tool which at least captured an element of

\footnotetext{
${ }^{10}$ Equation (9)is equivalent to equation (24) of Jones (1975). In Jones' equation the right hand side is identical to (9) when all intermediate input prices are distorted. The left hand side for Jones is the proportionate rate of change in the return to the sector specific factor, which is locally equal to the effective rate of protection under the current definition with all output prices distorted.
} 
general equilibrium. Equation (8) makes clear the sense in which the partial equilibrium measure is indeed part of a general equilibrium measure. Equation (8) thus partially legitimizes the applied economists' approach. However, the boundary of operationality has moved on in the last 25 years. For any specific factor Computable General Equilibrium (CGE) model, the effective rate of protection can be calculated for each sector j. Nearly all competitive CGE models use the specific factor construct in order to avoid 'excess specialization'. Thus for this class of models, effective protection is operational.

Section IV develops the effective protection index for models with increasing returns and imperfect competition. In this class of models too the profit function plays a key role, and entry is treated explicitly in somewhat the manner implied by the specific factor k. Recent CGE models of this type make such effective protection measures operational as well. 


\section{Effective Protection vs. Sector Specific Factor Income Changes}

With a CGE model the analyst can straightforwardly measure the proportionate income change for specific factors implied by the existing structure of protection as compared to free trade. This indeed is the theoretical tack of Jones (1975) and the main concern of the application of Kohler (1991). In special cases the usual effective rates have at least the sign and perhaps even the ranking of the factor income changes, but since the latter are available directly, at least with a CGE model, the former can be dispensed with. Does it follow that the new concept of effective protection can also be dispensed with? My answer is no.

The two questions, 'how much protection is given' and 'how much does income change as a result' are distinct. Sector specific factor income changes are a product of the level of protection given the sector (which the old effective protection concept tried to measure) and the rate at which the level of protection is translated into sector specific factoral income. Differences in income changes across sectors arise due to differences in both elements of the product, and the new concept gives a precise measure of the 'level' of protection in this context. Modern political economy makes the usefulness of a measure of the level of protection clear. In the influential model of Grossman and Helpman (1994), lobbies buy protection with contributions to a politician who trades off aggregate contributions against the aggregate welfare. The equilibrium generally yields a differentiated structure of protection. In this type of model the level of protection to each sector may usefully be defined as here ${ }^{11}$ to be the level of a uniform tariff on the distorted goods which achieves equal income (hence an equal contribution for the politician) for the sector specific factor. The higher the uniform tariff equivalent, the

\footnotetext{
${ }^{11}$ In Grossman and Helpman's model, the general equilibrium is so specialized that the nominal tariff is equal to the effective rate of protection under the new definition; the index number problem of this paper does not arise. However, Grossman and Helpman assume redistribution of the tariff revenue is incorporated in the lobby's objective function, which leads to an interest in lower tariffs for sectors other than the lobby's own.
} 
higher the general welfare loss associated (hypothetically) with compensating the specific factor interest. ${ }^{12}$ Thus the new concept gives a precise meaning to the idea of sectors buying a greater or lesser level of protection in an observed equilibrium.

The alternative measure, sectoral income changes due to the tariff structureis appropriate for other purposes of analysis. In the classic public economics view of the state, a rational benevolent planner potentially can alter policies. If the main concern of the analysis is income distribution, the income metric is appropriate, despite using an infeasible instrument --- lump sum taxation or subsidization --- to render the implications of the fiscal system comparable across sectors.

The distinction between the two metrics would not matter if the ranking of sectoral protection by the two measures were always the same. For the limiting case of all producer prices distorted, the two measures coincide. This follows from the homogeneity of the profit function and the definition of D:

$$
\pi\left(p^{1} / D, w\left(p^{1} / D\right)\right)=\pi\left(p^{1}, w\left(p^{1}\right)\right) / D=\pi\left(p^{0}, w\left(p^{0}\right)\right),
$$

hence

$$
D=\pi\left(p^{1}, w\left(p^{1}\right)\right) / \pi\left(p^{0}, w\left(p^{0}\right)\right) .
$$

But in general, a ranking of sectors by the proportionate change in income reflects both the level of the price changes and the sectoral conversion of given price changes into rent changes. This conversion depends on the share of the specific factor in value added and on various substitution parameters, as equation (8) makes clear. A simple counterexample provided in the Appendix shows that the two metrics can be perfectly negatively correlated in the usual case when only some producer prices are distorted. Generally the two metrics must give different rankings.

${ }^{12}$ Welfare is assumed to be monotonic in the uniform tariff for simplicity. 


\section{Extensions}

The model of sectoral protection afforded by a fiscal system presented in Section II can be extended in a number of ways, all of which are feasible with modern CGE models. In each case it is simply a matter of extending the model appropriately.

Nontraded goods are practically important in any model, and take on special significance in the imperfect substitutes (Armington) class of models which are most common for applied trade policy analysis. Here, no domestic firm makes a product which is a perfect substitute for an import.

\section{A. Nontraded Goods}

Nontraded goods have prices which are endogenously determined, similar to the prices of nontraded factors in Section II. Let the vector of home goods prices be denoted $h$, decomposed into intermediate and final goods price vectors denoted $h^{\mathrm{I}}$ and $\mathrm{h}^{\mathrm{F}}$. The first order condition for the intermediate goods prices implies market clearance of the domestic intermediate goods, with $\mathrm{h}^{\mathrm{I}}$ a function of $\mathrm{p}, \mathrm{h}^{\mathrm{F}}, \mathrm{v}$ and $\mathrm{k}$. As for final home goods prices, market clearance also determines them, the difference being that with final demand there are income effects. Handling this requires the additional structure of the trade expenditure function.

Suppose that aggregate demand follows the weak axiom of revealed preference, permitting use of the representative consumer model, with expenditure function $\mathrm{c}\left(\mathrm{p}, \mathrm{h}^{\mathrm{F}}, \mathrm{u}\right)$. The trade expenditure function is defined as ${ }^{13}$

$$
T(p, v, k, u)=\max _{w, h^{F}, h^{I}}\left\{c\left(p, h^{F}, u\right)-w^{\prime} v-\Pi\left(p, h^{F}, h^{I}, k\right)\right\}
$$

The sectoral profit vector in general equilibrium is defined by $\mathrm{T}_{\mathrm{kj}}(\mathrm{p}, \mathrm{v}, \mathrm{k}, \mathrm{u})$, the $\mathrm{jth}$ element being equal to $\pi \mathrm{j}$ as before. The full general equilibrium dependence of profits

\footnotetext{
${ }^{13}$ Nontraded intermediate goods with price vector $\mathrm{h}^{\mathrm{I}}$ result in a gross domestic product function defined by $\mathrm{g}\left(\mathrm{p}, \mathrm{h}^{\mathrm{F}}, \mathrm{v}, \mathrm{k}\right) \stackrel{\min }{=}\left\{\mathrm{w}^{\prime} \mathrm{v}+\prod\left(\mathrm{p}, \mathrm{h}^{\mathrm{F}}, \mathrm{h}^{\mathrm{I}}, \mathrm{w}, \mathrm{k}\right)\right\}$.
}

This is subsumed in the trade expenditure function. 
on $\mathrm{p}, \mathrm{v}, \mathrm{k}$ includes the dependence of $\mathrm{u}$ on the arguments $\mathrm{p}, \mathrm{v}, \mathrm{k}$, which comes through the social budget constraint or balance of trade requirement. (See Dixit and Norman, 1980.)

The effective rate of protection in sector $\mathrm{j}$ is defined by

$$
\begin{aligned}
& E=1 / D^{j}-1, \text { where } \\
& D^{j}\left(p^{1}, p^{0}, v, k\right)=D \mid T_{k_{j}}\left(p^{1} / D, v, k, u\left(p^{1} / D, v, k\right)\right)=T_{k_{j}}\left(p^{0}, v, k, u^{0}\right)
\end{aligned}
$$

or

$$
\begin{gathered}
D \mid \pi_{k}^{j}\left(p^{1} / D, h\left(p^{1} / D, v, k, u\left(p^{1} / D, v, k\right)\right), u\left(p^{1} / D, v, k\right)\right) \\
=\pi_{k}^{j}\left(p^{0}, h\left(p^{0}, v, k, u\left(p^{0}, v, k\right)\right), u\left(p^{0}, v, k\right)\right) .
\end{gathered}
$$

The alternative form of the price deflator shows that in contrast to the simple perfect substitutes case of section II, much of the action in (11) comes through cross effect terms $\mathrm{h}_{\mathrm{p}}$. The decomposition analogous to (8) is not revealing, since no home good has its price directly affected by an import tax. Nonetheless, (11) remains useful and operational in typical CGE models.

\section{B. Quotas}

Quotas can be handled using tools developed in Anderson and Neary (1992, 1994). A quota vector $q$ implies that the trade expenditure on non constrained goods is given by the distorted trade expenditure function:

$$
\widetilde{T}(q, p, v, k, u)=\max _{r}\left\{T(r, p, v, k, u)-r^{\prime} q\right\}
$$

where $r$ is the price vector of quota-constrained imports. The virtual (and market) price of $\mathrm{q}$ is equal to $-\widetilde{\mathrm{T}}_{\mathrm{q}}(\mathrm{q}, \mathrm{p}, \mathrm{v}, \mathrm{k}, \mathrm{u})=\mathrm{r}(\mathrm{q}, \mathrm{p}, \mathrm{v}, \mathrm{k}, \mathrm{u})$. Let $\mathrm{u}^{0}$ and $\mathrm{u}^{1}$ denote the equilibrium level of $u$ in the old and new equilibria respectively. Similarly $\mathrm{r}^{0}$ denotes the old domestic price of quota constrained imports, equal to $\mathrm{r}\left(\mathrm{q}^{0}, \mathrm{p}^{0}, \mathrm{v}, \mathrm{k}\right)$, and $\mathrm{r}^{1}$ denotes the new domestic price of quota constrained imports, equal to $\mathrm{r}\left(\mathrm{q}^{1}, \mathrm{p}^{1}, \mathrm{v}, \mathrm{k}\right)$. These prices are used to define tariff equivalents as part of forming an effective rate of protection. The effective rate of protection is defined by 


$$
\begin{aligned}
& E^{j}=1 / D^{j}-1 \\
& \begin{aligned}
D^{j}\left(q^{1}, p^{1} ; q^{0}, p^{0}\right)=D \mid & T_{k_{j}}\left(r^{1} / D, p^{1} / D, v, k, u\left(r^{1} / D, p^{1} / D, v, k\right)\right) \\
= & T_{k_{j}}\left(r^{0}, q^{0}, p^{0}, v, k, u^{0}\right)
\end{aligned}
\end{aligned}
$$

The first argument under $\mathrm{T}$ in (12) contains the virtual price vector. The virtual price and the new price $\mathrm{p}^{1}$ are deflated by the common tariff and tariff equivalent factor deflator.

The effective rate of protection in (12) is operational in CGE models set up to treat quotas explicitly.

\section{Imperfect Competition and Scale Economies}

The trick to treating profits in the present framework is to treat the firms output vector as analogous to a quota. The output vector is determined in a Nash equilibrium of a non cooperative game between firms, however, rather than being given by policy. For simplicity assume that $\mathrm{p}$ is the externally determined price vector of an imperfect substitute for the products of home firms. Also, for simplicity neglect endogenous changes in mobile factor prices and in real income of consumers. Let $\mathrm{Y}(\mathrm{p}, \mathrm{v}, \mathrm{k}, \mathrm{u})$ denote the Nash equilibrium output vector. The effective rate of protection for firm $\mathrm{j}$ is based on the deflator D such that:

$$
\pi^{j}\left(Y\left(p^{1} / D, v, k, u^{0}\right), v, k\right)=\pi^{j}\left(Y\left(p^{0}, v, k, u^{0}\right), v, k\right) .
$$

Scale economies can arise in this model, appearing in the potential that $\pi_{\mathrm{kk}}$ need not be negative. ${ }^{14}$ Endogenous mobile factor prices are straightforwardly included using the method of the previous section. Finally, a variety of market structures can be accommodated, with details determining the shape of $Y($.$) .$

\footnotetext{
${ }^{14}$ With increasing returns to scale technology and all factors variable, profits are unbounded and the profit function does not exist. The sector specific factor applied to the firm serves to bound profits if variable factors face ultimately diminishing returns. The profit function then exists but $\pi_{\mathrm{kk}}$ need not be positive.
} 


\section{Endogenous World Prices}

The final complication is endogenous world prices. The vector $\mathrm{p}$ is a function of the tariff factor vector $\tau$. To accommodate this, in previous operations where $\mathrm{p}^{1 / \mathrm{D}}$ appeared, it should be replaced by $\mathrm{p}\left(\tau^{1 / D}\right)$.

In all these case, the operationality of the index E depends on the existence of a CGE model which identifies rents. Computationally, obtaining E is then straightforward.

\section{Effective Protection Measures in US Agriculture}

Effective protection of US agriculture in 1982 is analyzed here with the use of the USDA/ERS computable general equilibrium model (Robinson et al., 1990), available from the GAMS library. The main purpose of the exercise is to illustrate the ease with which the concepts of this paper can be operationalized, given the availability of a CGE model. Secondarily, the results show that the old and new measures of effective protection are weakly correlated, with the calculated correlation coefficient not significantly different from zero. It is interesting to note that the largest deviations between the old and new measures are found among the agricultural sectors which the CGE model is designed to analyze.

The first subsection briefly summarizes the USDA/ERS model. For more details, see Robinson et al. (1990). The second subsection presents the results. The third subsection presents a sensitivity analysis.

\section{The USDA/ERS Model}

Computable general equilibrium (CGE) models are by now familiar to many readers, so the explanation which follows is brief. The USDA/ERS model is a small scale Walrasian model designed to focus on agriculture while achieving a consistency with general equilibrium.

The model has 5 agricultural sectors out of 10 total sectors. Demand is of the Armington variety, so that products are differentiated by place of origin. The US is assumed to be a price taker for its imports, but to face downward sloping import demand 
functions for its exports, with a parametric elasticity. The demand structure is a 2 level CES function, the lower level splitting demand between home and imported goods according to a CES subexpenditure function while the upper level allocates expenditure across the 10 sectors according to a Cobb-Douglas expenditure function. Three different types of households are distinguished (property owners, wage earners and transfer recipients), the differences in behavior between them coming through expenditure shares at the upper level. There is also parametric government consumption. Production requires intermediate inputs according to a Leontief technology, and primary inputs of capital, labor and land according to a Cobb-Douglas value added production function. I assume that 'capital' is fixed in each sector with labor and land being freely mobile between sectors (the original USDA/ERS model has capital mobile as well). Production in each sector is allocated between home sales and exports according to a CET transformation function, with an elasticity which differs across sectors.

The model is initialized on 1982 data. This includes consistent data on the inputoutput table, sectoral factor allocations, tariffs, factor taxes, commodity taxes, several types of government transfer, and government consumption. There is no treatment of nontariff barriers in the model, though these are highly significant in agriculture.

\section{Effective Protection of US Agriculture}

The basis results of the analysis are presented in Table 1 below. The cell entries are nominal and Effective Rates of Protection (ERPs). The Old ERP is the usual concept, the new ERP is the uniform tariff equivalent which holds constant the real income of the specific capital of the sector denoted by the row heading). The first 5 sectors are agricultural. They all receive nominal protection, though agricultural inputs are nearly unprotected. According to the old ERP concept, dairy and meat, and agricultural inputs receive negative effective protection. According to the new concept, both receive positive effective protection while other agriculture receives the most negative effective protection of nearly $6 \%$. Note that agricultural inputs, despite a trivial nominal tariff 
$(0.3 \%)$, leading to a $-8.4 \%$ ERP under the old concept, receive new ERP protection of nearly $1.4 \%$. Note also that under the old concept, agricultural processing (AGPROC) receives the highest effective rate of protection $(12.7 \%)$ while under the new concept it falls to the middle at just under $1 \%$. 
Table 1. Three Measures of Protection of US Agriculture Sector Nominal Old ERP New ERP Tariff

\begin{tabular}{|l|ccc}
\hline dairy and meat & 0.014 & -0.011 & 0.0164 \\
grains and oilseeds & 0.029 & 0.03 & 0.0378 \\
other agriculture & 0.037 & 0.034 & -0.0591 \\
agricultural processing & 0.115 & 0.127 & 0.0098 \\
agricultural inputs & 0.003 & -0.084 & 0.0138 \\
intermediate manufacturing & 0.018 & 0.04 & 0.0516 \\
final demand manufacturing & 0.027 & 0.025 & 0.0084 \\
trade and transport & 0.027 & 0.018 & 0.0108 \\
services & 0 & -1.938 & -0.0238 \\
real estate & 0 & -0.01 & $-8.40 \mathrm{E}-03$
\end{tabular}

As might be expected with these results, the correlation between the old and new ERPs is low, 0.334, which is not significantly different from zero. The correlation between the nominal tariff and the new ERP is nearly zero (0.022). The most dramatic aspect of the difference between the two concepts is seen in sign changes, however. In the agricultural sectors which are the focus of the model, 3 out of 5 ERPs change sign with the change in concept.

\section{Sensitivity Analysis}

An important potential difficulty with the use of CGE models is that elasticity parameters are not known with precision. To assess the significance of errors in the elasticities it is therefore customary to conduct sensitivity analysis. In practice, results are usually not sensitive to elasticity values, a finding replicated here for the most part. However, there are some notable exceptions to this rule.

The sensitivity analysis is based on varying the base case elasticity parameter by $50 \%$ upward and downward. There are a total of 23 elasticities to study: one substitution elasticity in consumption and production for each sector (20) plus 3 foreign import demand elasticities (for US exports), the remainder of US exports being assumed to face 
infinitely elastic demand. Most variations in elasticities result in changes in ERPs of much less than 50\%. Tables 2- and 3 below concentrate on the exceptions. As above, the cell entries are (new) ERPs. The row labels refer to tariffs designed to hold constant rental of capital in sectors 1 through 10, which have the same definition as the corresponding entries in the first column of Table 1. The column headings refer to the consumption elasticity parameter $\rho_{\mathrm{C}}$, the transformation elasticity parameter $\rho_{\mathrm{T}}$, and the demand for exports elasticity $\rho_{\mathrm{E}}$. The variation factor of .5 and 1.5 is applied to the base value of these. In Tables 2 and 3, the shaded cases are those for which the variation of the ERP due to elasticity changes is significant. Table 3 differs from Table 2 because sectors 4-10 do not have finite demand elasticities facing US exports. 
February 12, 1996

Effective Protection Redux

Table 2. ERP Sensitivity Analysis to Selected Agricultural Elasticities SENSITIVITY ANALYSIS TO SECTOR 2 ELASTICITIES

\begin{tabular}{|c|c|c|c|c|c|c|c|}
\hline \multicolumn{3}{|c|}{ RHOC (ARM. FCT. EXP.) } & \multicolumn{2}{|c|}{ RHOT(CET EXP) } & \multicolumn{2}{|c|}{ RHOE(EXP.EL.) } & \multirow[t]{2}{*}{ BASE LEVEL } \\
\hline variation & 0.5 & 1.5 & 0.5 & 1.5 & 0.5 & 1.5 & \\
\hline CAP1 & 0.0158 & 0.0171 & -0.012 & 0.03 & -0.016 & 0.033 & 0.0164 \\
\hline CAP2 & 0.0384 & 0.0372 & 0.084 & 0.021 & 0.134 & 0.0072 & 0.0378 \\
\hline CAP3 & -0.0594 & -0.0584 & -0.063 & -0.056 & -0.067 & -0.054 & -0.0591 \\
\hline CAP4 & 0.0095 & 0.0102 & 0.016 & 0.016 & -0.0064 & 0.018 & 0.0098 \\
\hline CAP5 & 0.0138 & 0.0138 & 0.0122 & 0.0145 & 0.011 & 0.015 & 0.0138 \\
\hline CAP6 & 0.0515 & 0.05116 & 0.048 & 0.053 & 0.042 & 0.056 & 0.0516 \\
\hline CAP7 & 0.0083 & 0.0084 & 0.0065 & 0.0091 & 0.0023 & 0.0112 & 0.0084 \\
\hline CAP8 & 0.0108 & 0.0108 & 0.0098 & 0.011 & 0.0085 & 0.0119 & 0.0108 \\
\hline CAP9 & -0.0239 & -0.0237 & -0.0253 & -0.023 & -0.0262 & -0.023 & -0.0238 \\
\hline CAP10 & -0.0084 & -0.0084 & -0.0076 & -0.009 & -0.0073 & -0.009 & -0.0084 \\
\hline
\end{tabular}

SENSITIVITY ANALYSIS TO SECTOR 3 ELASTICITIES

\begin{tabular}{llcccccc}
\multicolumn{2}{c}{ RHOC (ARM. FCT. EXP.) } & \multicolumn{2}{c}{ RHOT(CET EXP) } & \multicolumn{2}{c}{ RHOE(EXP.EL.) } & BASE LEVEL \\
variation & 0.5 & 1.5 & 0.5 & 1.5 & 0.5 & 1.5 & \\
CAP1 & $\mathbf{0 . 0 0 7 1}$ & $\mathbf{0 . 0 0 2 2}$ & 0.0157 & 0.0169 & 0.0152 & 0.0171 & $\mathbf{0 . 0 1 6 4}$ \\
CAP2 & 0.04 & 0.0357 & 0.0381 & 0.0377 & 0.0386 & 0.0375 & 0.0378 \\
CAP3 & $\mathbf{0 . 3 3 2 8}$ & $\mathbf{0 . 0 2}$ & -0.061 & -0.058 & -0.072 & -0.051 & -0.0591 \\
CAP4 & 0.0047 & 0.0136 & 0.009 & 0.0101 & 0.0092 & 0.0101 & 0.0098 \\
CAP5 & 0.0131 & 0.0144 & 0.0138 & 0.0138 & 0.0136 & 0.0139 & 0.0138 \\
CAP6 & 0.0501 & 0.052 & 0.0514 & 0.0517 & 0.0509 & 0.052 & 0.0516 \\
CAP7 & 0.006 & 0.0102 & 0.0083 & 0.0084 & 0.0079 & 0.0086 & 0.0084 \\
CAP8 & 0.0101 & 0.0114 & 0.0108 & 0.0108 & 0.0107 & 0.0109 & 0.0108 \\
CAP9 & -0.024 & -0.039 & -0.0239 & -0.024 & -0.024 & -0.024 & -0.0238 \\
CAP10 & -0.0098 & -0.0073 & -0.0084 & -0.008 & -0.0086 & -0.008 & -0.0084
\end{tabular}


February 12, 1996

Effective Protection Redux

Table 3. ERP Sensitivity Analysis to Other Selected Elasticities SENSITIVITY ANALYSIS TO SECTOR 4 ELASTICITIES RHOC (ARM. FCT. EXP.) RHOT(CET EXP) BASE LEVE

$\begin{array}{llcccc}\text { variation } & 0.5 & 1.5 & 0.5 & 1.5 & \\ \text { CAP1 } & \mathbf{0 . 0 0 9} & \mathbf{0 . 0 4 1 2} & 0.0182 & 0.0153 & \mathbf{0 . 0 1 6 4} \\ \text { CAP2 } & 0.0359 & 0.0413 & 0.0413 & 0.0371 & 0.0378 \\ \text { CAP3 } & -0.062 & -0.056 & -0.057 & -0.06 & -0.0591 \\ \text { CAP4 } & 0.0069 & 0.012 & 0.0098 & 0.0098 & 0.0098 \\ \text { CAP5 } & 0.0141 & 0.0135 & 0.0138 & 0.0138 & 0.0138 \\ \text { CAP6 } & 0.0563 & 0.047 & 0.0501 & 0.053 & 0.0516 \\ \text { CAP7 } & 0.0097 & 0.0071 & 0.0084 & 0.0083 & 0.0084 \\ \text { CAP8 } & 0.011 & 0.0106 & 0.0108 & 0.0108 & 0.0108 \\ \text { CAP9 } & -0.024 & -0.024 & -0.024 & -0.024 & -0.0238 \\ \text { CAP10 } & -0.009 & -0.008 & -0.008 & -0.009 & -0.0084\end{array}$

SENSITIVITY ANALYSIS TO SECTOR 5 ELASTICITIES

\begin{tabular}{lccccc}
\multicolumn{2}{c}{ RHOC (ARM. FCT. EXP.) } & \multicolumn{2}{c}{ RHOT(CET EXP) } & BASE LEVE \\
variation & 0.5 & 1.5 & 0.5 & 1.5 & \\
CAP1 & 0.017 & 0.0159 & 0.0168 & 0.0161 & 0.0164 \\
CAP2 & 0.0371 & 0.0369 & 0.0376 & 0.038 & 0.0378 \\
CAP3 & -0.058 & -0.06 & -0.064 & -0.054 & -0.0591 \\
CAP4 & 0.0101 & 0.0095 & 0.0101 & 0.0095 & 0.0098 \\
CAP5 & 0.0093 & 0.019 & 0.0086 & 0.016 & 0.0138 \\
CAP6 & 0.0493 & 0.054 & $\mathbf{0 . 0 5 2}$ & $\mathbf{0 . 1 6 6}$ & $\mathbf{0 . 0 5 1 6}$ \\
CAP7 & 0.0099 & 0.0074 & 0.009 & 0.0072 & 0.0084 \\
CAP8 & 0.0109 & 0.0107 & 0.0109 & 0.0107 & 0.0108 \\
CAP9 & -0.024 & -0.024 & -0.024 & -0.024 & -0.0238 \\
CAP10 & -0.008 & -0.008 & -0.008 & -0.008 & -0.0084
\end{tabular}

SENSITIVITY ANALYSIS TO SECTOR 6 ELASTICITIES RHOC (ARM. FCT. EXP.) RHOT(CET EXP) BASE LEVE

$\begin{array}{lccccc}\text { variation } & 0.5 & 1.5 & 0.5 & 1.5 & \\ \text { CAP1 } & 0.0193 & 0.0142 & 0.0177 & 0.0152 & 0.0164 \\ \text { CAP2 } & 0.0437 & 0.0297 & 0.0378 & 0.0378 & 0.0378 \\ \text { CAP3 } & -0.054 & -0.063 & -0.071 & -0.05 & -0.0591 \\ \text { CAP4 } & 0.0113 & 0.0086 & 0.0109 & 0.0088 & 0.0098 \\ \text { CAP5 } & \mathbf{0 . 0 1 6} & \mathbf{0 . 1 2 2} & 0.0149 & 0.0128 & \mathbf{0 . 0 1 3 8} \\ \text { CAP6 } & \mathbf{0 . 0 2 9} & \mathbf{0 . 1 0 5} & 0.059 & 0.048 & \mathbf{0 . 0 5 1 6} \\ \text { CAP7 } & 0.0135 & 0.0089 & 0.0117 & 0.007 & 0.0084 \\ \text { CAP8 } & 0.011 & 0.0102 & 0.0113 & 0.0104 & 0.0108 \\ \text { CAP9 } & -0.024 & -0.024 & -0.023 & -0.025 & -0.0238 \\ \text { CAP10 } & -0.009 & -0.008 & -0.008 & -0.008 & -0.0084\end{array}$


The first row of Table 2 has an example of a sign change due to a shift in both the demand elasticity and the supply elasticity in sector 2 . The second panel of Table 2 refers to the effect of changes in elasticities in sector 3 , and here there are two examples of nonmonotonic relationships between the consumption elasticity in sector 3 and the ERP in sectors 1 and 3. For the latter, the ERP changes sign in the interval between the high and low values. Other shaded values here and in Table 3 merely have large monotonic signpreserving changes. The shaded cases are not confined to 'own' effects; 6 of the 9 are cross effects. Also, the shaded cases are due to variation in all 3 classes of elasticity. The problematic cases number 9 out of 230 , which might be interpreted as a trivial incidence. But even a small incidence of sign changes and non-monotonicity is troublesome. It is difficult to avoid the conclusion that elasticities may matter in calculating the new version of ERPs. Thus sensitivity analysis will always be needed in any application. ${ }^{15}$

In contrast to the rather negative results of the sensitivity analysis, the simulation results showed that existence and uniqueness were not practical problems. Forcing a wide range of starting values always produced the same equilibrium. This point is particularly worth noting because the non-monotonicity reported above might otherwise reflect multiple equilibria.

\section{Conclusion}

This note rehabilitates the notion of effective protection. The effective rate of protection of a sector is defined to be the uniform tariff which has the same impact on the profit of the sector as the actual tariff structure. Modern index number and duality theory is used to develop its properties. In partial equilibrium with fixed coefficients, the new definition gives a formula identical to the usual effective rate of protection formula.

\footnotetext{
15It is possible to manipulate a simplified version of the specific factors general equilibrium model to gain some insight into why the ERP may not be one-signed as the elasticities vary. However, the limited analytic results do not hold with any generality so they are not reported here. The relationships reflected in the numbers of Tables 2 and 3 are inherently highly nonlinear and complex, and require simulation.
} 
With substitution among intermediate inputs, the new definition implies a simple variant on the standard formula. In general equilibrium the new definition implies a well defined index which decomposes intuitively. One component is the partial equilibrium formula, leading to a special case where the partial equilibrium formula gives the same sectoral ranking of effective rates of protection as the general equilibrium formula. The decomposition makes clear how very special this case is, leading back to the necessity of measuring the effective rate of protection in a general equilibrium model.

Modern trade policy analysis is typically conducted with one or more CGE models as an important element. These models usually have sectorally specific factors. Thus the effective rate of protection is typically operational. The sample results of Section V show that the new and old concepts of effective protection give very different pictures of the pattern of protection afforded to sectors by the actual tariff structure. It will be interesting in the future to use the effective rate of protection to study the implications of various national tariff structures and various economists' production/preference structures expressed in their CGE models. Specifically, it should be instructive to rank the protection to specific factors in a set of industries and see how it changes with different protection structures (tariff reforms) and with different production structures (sensitivity analysis). Second, some of the most interesting distributional issues about trade policy concern the sectoral rents, and this can be illuminated by the new ERP and its relation to the changes protection induces in sectoral rents. Third, it is at least arguable that political economy models may have sufficiently sophisticated players that the new concept $\mathrm{E}$ rather than the old concept e or the nominal tariff $\mathrm{t}$ is the focus of their lobbying efforts. It will be interesting to relate $\mathrm{E}$ to measures suggested by political economy as capturing the ability of sectoral interests to compete in political markets. 


\section{References}

Anderson, James E. (1994), "The Theory of Protection" in David Greenaway and L. Alan Winters eds. Surveys of International Trade, Oxford: Basil Blackwell.

Anderson, James E. and Seiji Naya (1969), "Substitution and Two Concepts of Effective Rate of Protection", American Economic Review, 59, 607-12.

Anderson, James E. and J. Peter Neary (1995), "Domestic Distortions and International Trade", International Economic Review, forthcoming. (1994), "Measuring the Restrictiveness of Trade

Policy", World Bank Economic Review, $\underline{8}, 151-70$.

Corden, W. Max (1966), "The Structure of a Tariff System and the Effective Protective Rate", Journal of Political Economy, 74, 221-37.

Deaton, A. (1979), "The Distance Function and Consumer Behavior, with Applications to Index Numbers and Optimal Taxation", Review of Economic Studies, $\underline{46}$, 391-405.

Deaton, A. and J. Muellbauer, (1980), Economics and Consumer Behavior, Cambridge: Cambridge University Press.

Dixit, Avinash (1985), "Tax Policy in Open Economies" in Alan Auerbach and Martin Feldstein eds. Handbook of Public Economics, Amsterdam: North-Holland.

Dixit, Avinash and Victor Norman (1980), Theory of International Trade, Cambridge: Cambridge University Press.

Ethier, Wilfrid J. (1971), "General Equilibrium Theory and the Concept of Effective Protection" in Herbert Grubel and Harry Johnson eds. Effective Tariff Protection, Geneva: GATT, 17-44.

Ethier, Wilfrid J. (1977), "The theory of effective protection in general equilibrium: effective rate analogues of nominal rates", Canadian Journal of Economics, 10, 233-245. 
Grossman, Gene and Elhanan Helpman (1994), "Protection for Sale", American Economic Review, 84, 833-850.

Jones, Ronald W. (1975), "Income Distribution and Effective Protection in a Multicommodity Trade Model”, Journal of Economic Theory, 11, 1-15.

Kohler, Wilhelm (1992), "Income Distribution and Labor Market Effects of Austrian pre and post-Tokyo Round Tariff Protection”, European Economic Review, 35, 139-54.

Robinson, S., M. Kilkenny and K. Hanson (1990), "The USDA/ERS Computable General Equilibrium Model of the United States, USDA/ERS Staff Report No. AGES 9049, Washington, DC.

Tan, Augustine H. H. (1970), "Differential Tariffs, Negative Value Added and the Theory of Effective Protection", American Economic Review, 60, 107-116. 


\section{Appendix 1. Tax Rate Metrics vs. Profit Metrics}

The simplest possible comparison arises with two sectors in partial equilibrium, neither of which supplies inputs to the other. The rest of the producer prices in the economy are assumed to be undistorted, and very large relative to the distorted sectors. The effective protection metric is simply the sectoral output tariff, which delivers an effective subsidy at the same rate. The profit metric is the proportional rise in the profit induced by the subsidy. The figure shows a case in which the sector with the larger percentage subsidy enjoys the smaller percentage increase in profits. The supply function goes through the origin because the fixed factors receive 'profits'. Supply curves slope upward but theory does not restrict the second derivative, and industry 2 has increasing slope while industry 1 has decreasing slope. 


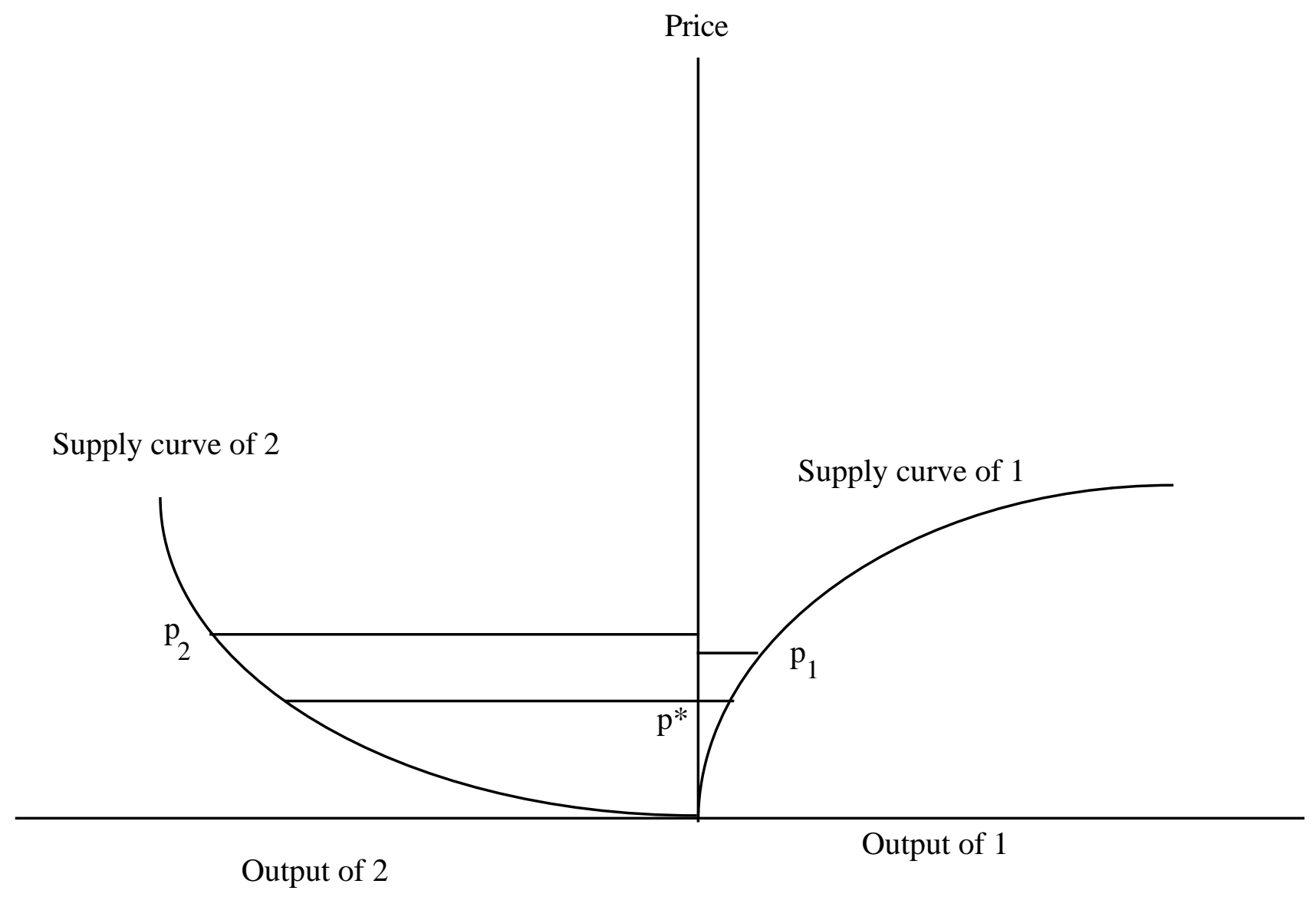

The two sectors have units chosen such that the free trade price $\mathrm{p}^{*}$ is common. The tariff structure gives sector 2 a larger rise in supply price than sector 1 . Profits are given by the area behind the supply curve, and as drawn the proportionate rise in profits is larger in sector 1 than in sector 2 .

The counterexample can be avoided if the supply functions are linear ${ }^{16}$, but this is clearly too extreme a sufficient condition. Thus the effective protection metric generally differs from the profit metric.

\footnotetext{
${ }^{16}$ Let the slope of a linear supply curve be equal to a. The change in the area behind the supply curve is equal to $(a / 2)\left[p^{2}-p^{* 2}\right]$, so the proportional change in the area is equal to $\left(p / p^{*}\right)^{2}-1$, which is monotonic in the tariff and independent of the slope. Similar triangles can be used to prove this in the figure.
} 


\section{Appendix 2. Existence and Uniqueness}

The existence and uniqueness problems are essentially the same for partial and general equilibrium versions of the index, so except for parenthetic comment the exposition will stick to the partial equilibrium version. Let $\mathrm{w}$ denote the vector of nondistorted prices (possibly even including some output prices) and let $\mathrm{p}$ denote the vector of distorted prices. A generic sector has a convex profit function $\pi(\mathrm{p}, \mathrm{w})$, where the sectoral index $\mathrm{j}$ is omitted to avoid notational clutter. The initial prices are $\mathrm{p}^{0}, \mathrm{w}^{0}$. The new distorted price vector is $\mathrm{p}^{1}$. The effective protection index is defined following the text based on

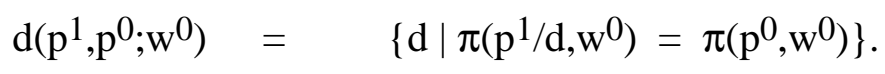

The problem is, when is defined and when is it unique?

In the definition of $\mathrm{d}$, the function $\pi\left(\mathrm{p}^{1} / \mathrm{d}, \mathrm{w}^{0}\right)$ may be considered as a function of $d$ alone, $f(d)$. Since $\pi$ is convex in $p, f(d)=\pi\left(p^{1 / d, w^{0}}\right)$ is concave in $d$. However, $f^{\prime}(d)$ need not generally be one-signed. The existence problem is illustrated in the diagram below, in which d does not exist. 


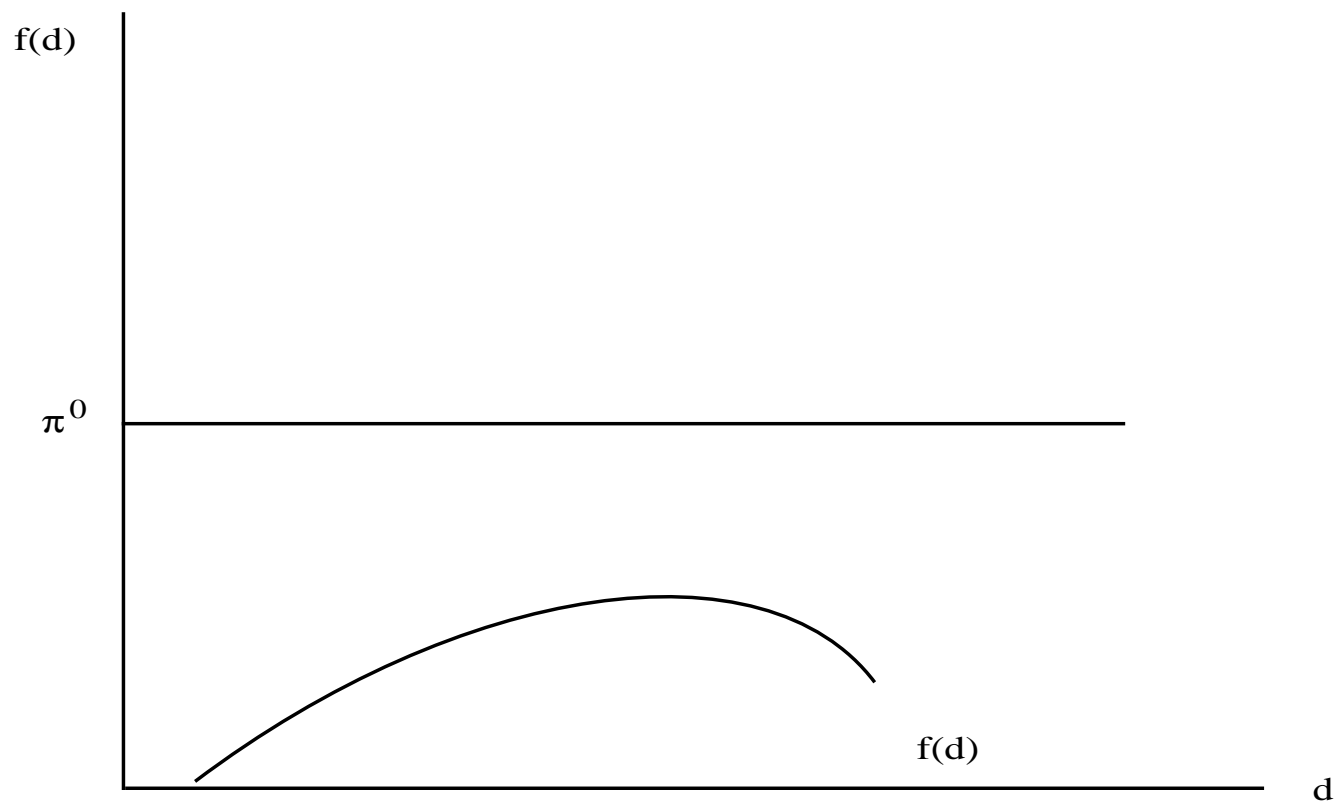

In some cases, it is possible to restrict f'(d) to one sign and hence prove the existence for all prices $\mathrm{p}^{1}$ in the positive orthant. One case where all positive prices admit a definition of $d$ is illustrated below. The profit function is mapped for one distorted output price and one distorted input price. With non-negative profit and a nondistorted input, the minimum output price associated with a non-negative profit level must be positive: the convex isoprofit contour must hit the vertical axis. Then any point in the positive quadrant defines a ray from the origin through $\pi^{0} ; \mathrm{d}$ exists (and is unique). 


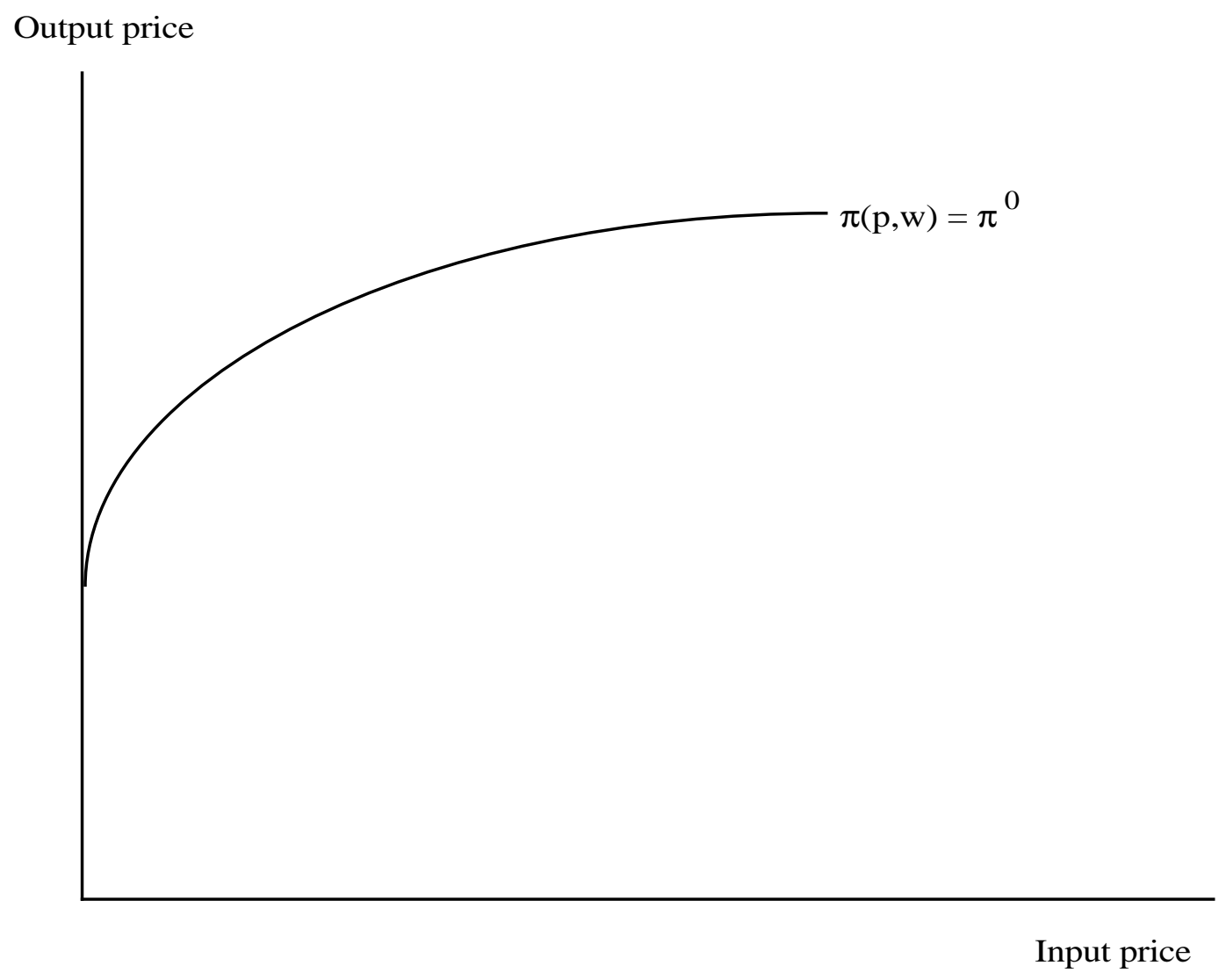

Possible non-existence arises with more than one output, since it is not possible to guarantee that the projection of the isoprofit contour hits the vertical axis for nonnegative profits. If the contour hits the horizontal axis, $d$ does not exist unless $\mathrm{p}^{1}$ is restricted to a half-space below and to the right of the ray from the origin which is tangent to the isoprofit contour. The restriction is illustrated in the next diagram: prices must lie in the convex set bordered with heavy lines called the minimal support set.. 


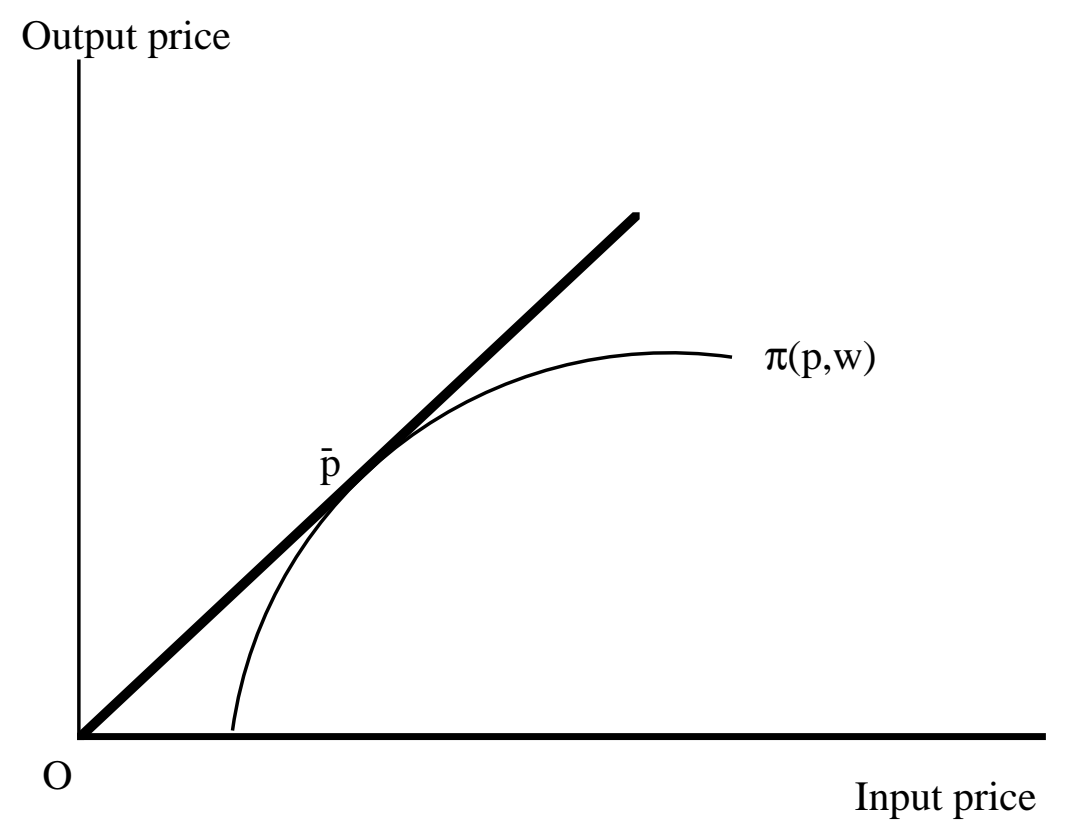

Formally, the minimal support set $\mathrm{P}$ is based on the minimal support price $\overline{\mathrm{p}}$ : $\overline{\mathrm{p}}\left(\mathrm{w}^{0}\right)=\mathrm{p}: \pi_{\mathrm{p}}\left(\mathrm{p}, \mathrm{w}^{0}\right)^{\prime} \mathrm{p}=0$.

$\overline{\mathrm{p}}$ is the price vector of distorted prices for which the contribution of distorted prices to the given level of $\pi$ is equal to zero. The minimal support set $\mathrm{P}$ is defined by

$$
\mathrm{P}\left(\mathrm{w}^{0}\right)=\quad\left\{\mathrm{p} \mid \pi_{\mathrm{p}}\left(\overline{\mathrm{p}}, \mathrm{w}^{0}\right)^{\prime} \mathrm{p} \leq 0, \mathrm{p} \geq 0\right\} .
$$

(This requirement can be extended to the general equilibrium version of effective protection, replacing $\pi$ with $g_{k}$.) The minimal support set expresses the requirement that the new prices not provide more support to profits than the minimal support price $\bar{p}$.

The uniqueness issue is illustrated in the first diagram. Assuming existence, $\pi^{0}$ at a level such that it intersects $\mathrm{f}, \mathrm{f}(\mathrm{d})$ could have two solutions in $\mathrm{d}$. Whether it does or not is, however, of no economic relevance. The definition of $\mathrm{d}$ implies that at $\mathrm{p}^{1}$, the direction of change of $\pi\left(\mathrm{p}^{1 / \mathrm{d}, \mathrm{w})}\right.$ with respect to $\mathrm{d}$ together with the sign of $\pi\left(\mathrm{p}^{1}, \mathrm{w}^{0}\right)$ $\pi\left(\mathrm{p}^{0}, \mathrm{w}^{0}\right)$ can be appied to determine the direction in which to move $\mathrm{d}$. There would be no economic sense in driving the distorted price deflator across the sign change point (where $\mathrm{f}$ is at its maximum). 


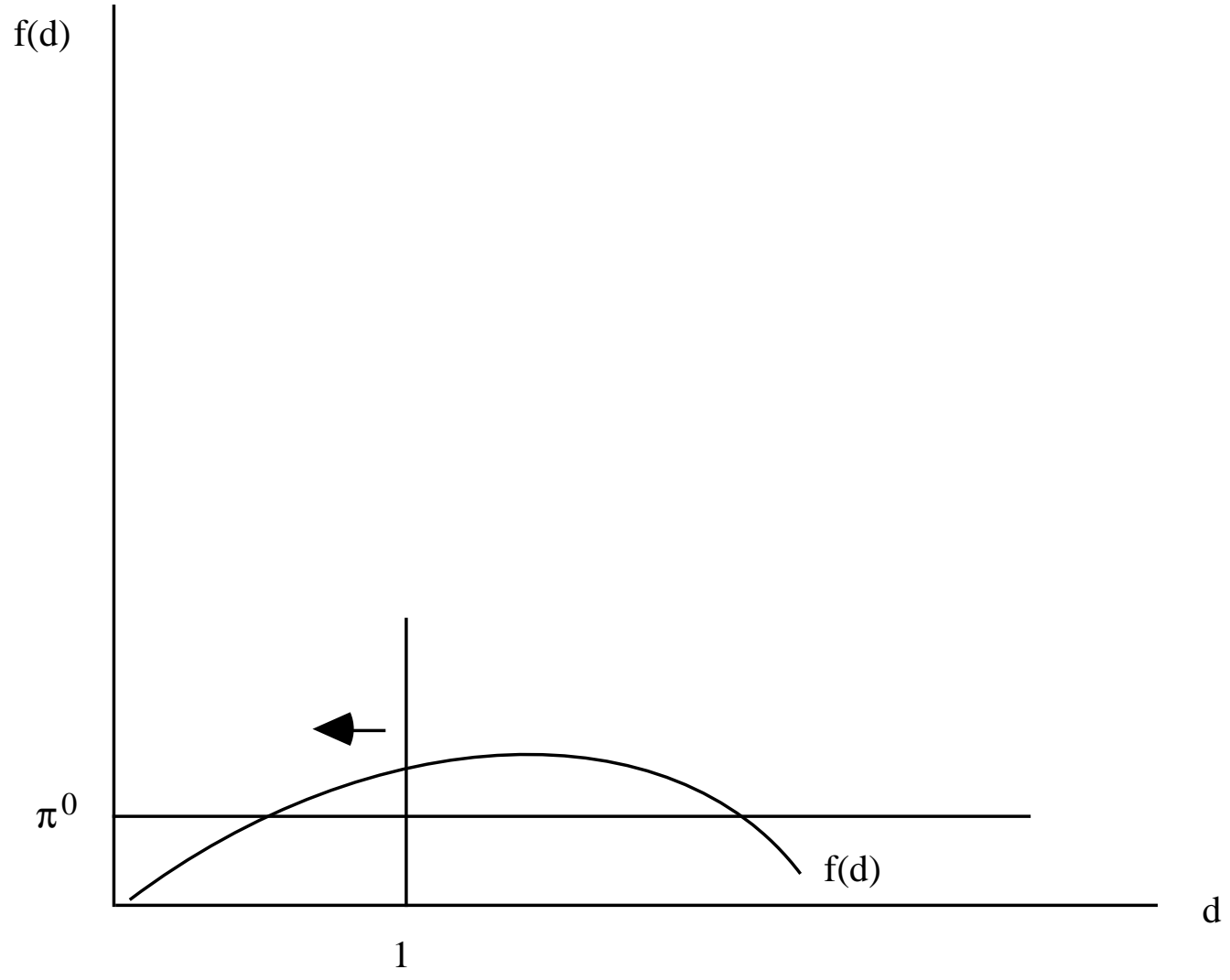

(The discussion here has been entirely in terms of the partial equilibrium profit function.

However, the logic uses only convex structure, which carries over the the general equilibrium structure $\left.\mathrm{g}_{\mathrm{k}}(\mathrm{p}, \mathrm{v}, \mathrm{k})\right)$. 